\title{
Yamaç Duraylılığı Araştırmalarında 2D ve 3D FEM-SSR Yöntemlerinin Uygulanması: Borçka (Artvin) Yöresinden Örnek Bir Çalışma
}

\author{
Application of the 2D and 3D FEM-SSR Methods in Slope Stability Investigations: A Case \\ Study from Borçka (Artvin) Region
}

\begin{abstract}
Ayberk KAYA*
Recep Tayyip Erdoğan Üniversitesi, Mühendislik Fakültesi, Jeoloji Mühendisliği Bölümü, 53100, Rize

• Geliş tarihi / Received: 30.05.2018 • • Düzeltilerek geliş tarihi / Received in revised form: 01.09.2018 • Kabul tarihi / Accepted: 21.09.2018

$\ddot{O} z$

Bu çalışma kapsamında Yeniyol (Borçka-Artvin) Mahallesi'deki yeni devlet hastanesinin inşaatı için açılan zemin şevinde meydana gelen duraysızlık problemi mühendislik jeolojisi açısından incelenmiştir. Yapılan çalışmalar sırasıyla arazi, laboratuvar ve duraylılık analizi çalışmaları olmak üzere üç aşamada yürütülmüştür. Bu amaçla toplam $108 \mathrm{~m}$ derinliğinde 3 adet sondaj kuyusu açılmış, 1 profilde jeofizik çalışmalar gerçekleştirilmiş ve 1 sondaj kuyusunda inklinometre ölçümleri yapılmıştır. Arazi çalışmaları sonucunda ana kayayı Eosen yaşlı Kabaköy Formasyonu'na ait volkanik kayaçların oluşturduğu ve bu birimlerin üzerine alttan üstte doğru kumlu-çakıllı ve killi-siltli olmak üzere iki seviyeden oluşan yamaç molozunun geldiği saptanmıştır. Yamaç molozunun fiziko-mekanik özelliklerini belirlemek için araştırma sondajlarından örselenmemiş örnekler alınmıştır. Arazi ve laboratuvar çalışmalarından elde edilen veriler yardımıyla sonlu elemanlar tabanlı 2D ve 3D Kayma Dayanımı Azaltma Yaklaşımı (FEM-SSR) yöntemleri kullanılarak duraylılık analizleri yapılmış ve sonuçlarının birbiriyle uyumlu olduğu saptanmıştır. Sonuç olarak kazı şevinde önlem alınmaması durumunda önüne geçilemez mühendislik sorunlarıyla karşılaşılacağı belirlenmiştir. Destekleme yöntemi olarak ise fore kazık uygulamasının yapılması önerilmektedir.
\end{abstract}

Anahtar kelimeler: Duraylılık analizi, 2D ve 3D FEM-SSR yöntemi, İnklinometre ölçümleri

\begin{abstract}
In the scope of this study, the stability problem in the soil slope excavated for the construction of the new government hospital in the Yeniyol (Borçka-Artvin) quarter was investigated in terms of engineering geology. The studies were performed in three stages as field, laboratory works and stability analyses. For this purpose, three boreholes with a total of 108 meters in length were drilled, geophysical studies were performed along the one line and inclinometer measurements were taken in one borehole. The talus consisting of two levels as sandy-gravelly and silty-clayey soils overlies the Eocene-aged Kabaköy Formation comprising the volcanic rocks. To determine the physico-mechanical properties of talus, undisturbed samples were taken from boreholes. $2 D$ and $3 D$ FEM-SSR stability analyses were evaluated using the obtained data from field and laboratory studies. It was determined that the stability analyses results are compatible with each other. As a result, it was determined that unforeseen engineering problems will be encountered if measures are not taken in the slope. It is suggested to apply fore pile application as support method.
\end{abstract}

Keywords: Stability analysis, 2D and 3D FEM-SSR method, Inclinometer measurements

\footnotetext{
* Ayberk KAYA; ayberkkaya@hotmail.com; Tel: (0464) 2337518 (dâhili: 1175); orcid.org/0000-0001-7278-333X
} 


\section{Giriş}

Ülkemizde meydana gelen doğal kaynaklı afet olayları içerisinde en yaygın olarak görülenlerden biri olan heyelanlar özellikle Doğu Karadeniz Bölgesi'nde çoğu zaman önemli ekonomik zararlarla birlikte can kayıplarına da neden olmaktadır. $\mathrm{Bu}$ bölgede kütle hareketlerinin meydana gelmesinde aşırı yağışların, yükssek yamaç eğiminin, akarsu aşındırmalarının ve insan kaynaklı müdahalelerin etkili olduğu görülmektedir. $\mathrm{Bu}$ tür duraysızlık problemlerinin araştırılmasında en uygun analiz yönteminin kullanılması elde edilecek sonuçların güvenirliği açısından önem taşımaktadır. İki boyutlu (2D) şev duraylilık analizleri jeoloji, maden ve inşaat mühendisleri tarafindan yaygın olarak kullanılmaktadır. Ancak, duraysızlık problemleri gerçekte üç boyutludur (3D). Genel olarak 3D yaklaşımlarının 2D yaklaşımlarına kıyasla daha tutucu olduğu kabul edilmektedir. Ayrıca, 2D analizleriyle belirlenen güvenlik sayısı sadece üç boyutlu şevin kritik bölümünden alınan kesitler için doğrudur. Dolayısıyla çoklu 2D analizleri yaparak kritik kesiti belirlemek zaman alıcı bir süreçtir. $\mathrm{Bu}$ nedenle duraylılık analizlerinde 3D modellerinin kullanılması şev tasarımlarını daha ekonomik hale getirerek tasarımcılar için yol gösterici bir rehber olmaktadır. Dış yüklerin etkisi altındaki bir şevin duraylılığı analitik eleman yöntemi (AEM), sınır eleman yöntemi (BEM), sonlu farklar yöntemi (FDM), ayrık eleman yöntemi (DEM) ve sonlu eleman yöntemi (FEM) gibi geliştirilmiş birçok sayısal yöntem ile analiz edilebilmektedir. Ancak bu yöntemlerin içinde FEM tabanlı Kayma Dayanımı Azaltma Yaklaşımı (FEM-SSR), bilgisayar teknolojisindeki hızlı gelişmelere bağlı olarak son yıllarda araştırmacılar tarafindan sıklıkla tercih edilmektedir (Cheng vd., 2005; Griffiths ve Marquez, 2007; Gürocak vd., 2008; Wei vd., 2009; Xiaolei vd., 2013; Alemdağ vd., 2014, 2015; Kaya vd., 2016a, 2016b, 2017, 2018; Kaya, 2017; Singh vd., 2017).

$\mathrm{Bu}$ çalışmada Yeniyol (Borçka-Artvin) Mahallesi'deki yeni devlet hastanesinin inşaatı için açılan zemin şevinde meydana gelen duraysızlık problemi mühendislik jeolojisi açısından araştırılmıştır. 1/25000 ölçekli Artvin F47-a3 paftası içinde bulunan çalışma alanı, eski bir heyelan (paleo heyelan) malzemesinin oluşturduğu $10-20^{\circ}$ eğim açısı ile batı yönüne bakan bir yamacın üzerindedir (Şekil 1). Çalışma alanı ve çevresi için yapılan üç boyutlu topografik incelemede tipik bir heyelan morfolojisi özelliğini sunduğu saptanmıştır. İnşaat alanında kazı öncesinde toplam $85 \mathrm{~m}$ derinliğinde 5 adet, duraysız alanda ise toplam $108 \mathrm{~m}$ derinliğinde 3 adet araştırma sondajı açılmıştır. 1 adet sondaj kuyusundan inklinometre ölçümleri alınmış ve 1 profilde ise sismik kırılma yöntemi yardımıyla jeofizik çalışmalar gerçekleştirilmiştir. Laboratuvar çalışmaları kapsamında araziden temin edilen örselenmemiş ve örselenmiş zemin örnekleri üzerinde çalışmanın amacına uygun zemin mekaniği deneyleri gerçekleştirilmiştir. Arazi ve laboratuvar çalışmalarından elde edilen veriler yardımıla 2D ve 3D FEM-SSR yöntemleri kullanılarak duraysızlık sorunu gözlenen şev için analizler yapılmış ve duraylılığını sağlaması için destek önerilerinde bulunulmuştur.

\section{2. İnceleme Alanı ve Çevresinin Jeolojisi}

Doğu Pontid Tektonik Birliği'nin Kuzey Zonu'nda yer alan çalışma alanı ve çevresinde (Ketin, 1966) Kabaköy Formasyonu'na ait kayaçlar ile yamaç molozları ve alüvyonlar yüzeyleme vermektedir. Tipik olarak Kabaköy (Gümüşhane) Yöresi'nde yüzeyleme veren ve genellikle kırıntılı çökellerle başlayıp üste doğru volkanik karakterde olan birim, ilk olarak Güven (1993) tarafindan Kabaköy Formasyonu olarak tanımlanmıştır. Genel olarak bazalt-andezit ve bunların piroklastitlerinden oluşan formasyonda koyu gri renk tonu hakimdir. Birimin yaşı, yapılan önceki çalışmalarda Eosen olarak belirlenmiştir.

Yamaç molozu olarak tanımlanan zemin malzemesi çalışma alanının üstünde bulunduğu yamacın eteğinde yoğun bir biçimde gözlenmekte olup, yamacın bulunduğu alandaki kayaç türlerine göre köşeli, yassı ve bazıları küt köşeli, blok, çakı1, kum, silt ve killerden oluşmuşlardır. Silt ve kil miktarı diğer elemanlara göre daha yüksektir. Bloklar Kabaköy Formasyonu'ndan türemiş bazalt karakterli köşeli volkanik kayaçlardan oluşmaktadır. Çalışma alanında yüzeylenen heyelan kökenli yamaç molozunda yapılan arazi, sondaj ve jeofizik çalışmaları neticesinde birimin üstten alta doğru killi-siltli ve kumlu-çakıllı olmak üzere iki seviyeden oluştuğu belirlenmiştir.

Alüvyonlar çalışma alanı ve çevresinde irili ufaklı akarsu vadilerinde oluşmuş kumlu, siltli, çakıllı ve bloklu malzemelerden oluşmaktadır. Çoruh Nehri'nin yatağında en yoğun şekilde gözlenmektedir. Çoğunlukla çakılların oluşturduğu alüvyonlarda bloklar da sıkça görülmektedir. Bloklar ve çakıllar genellikle yuvarlak, bazıları küt köşelidir. Çalışma alanı ve çevresine ait jeoloji haritası Şekil 2'de verilmiştir. 


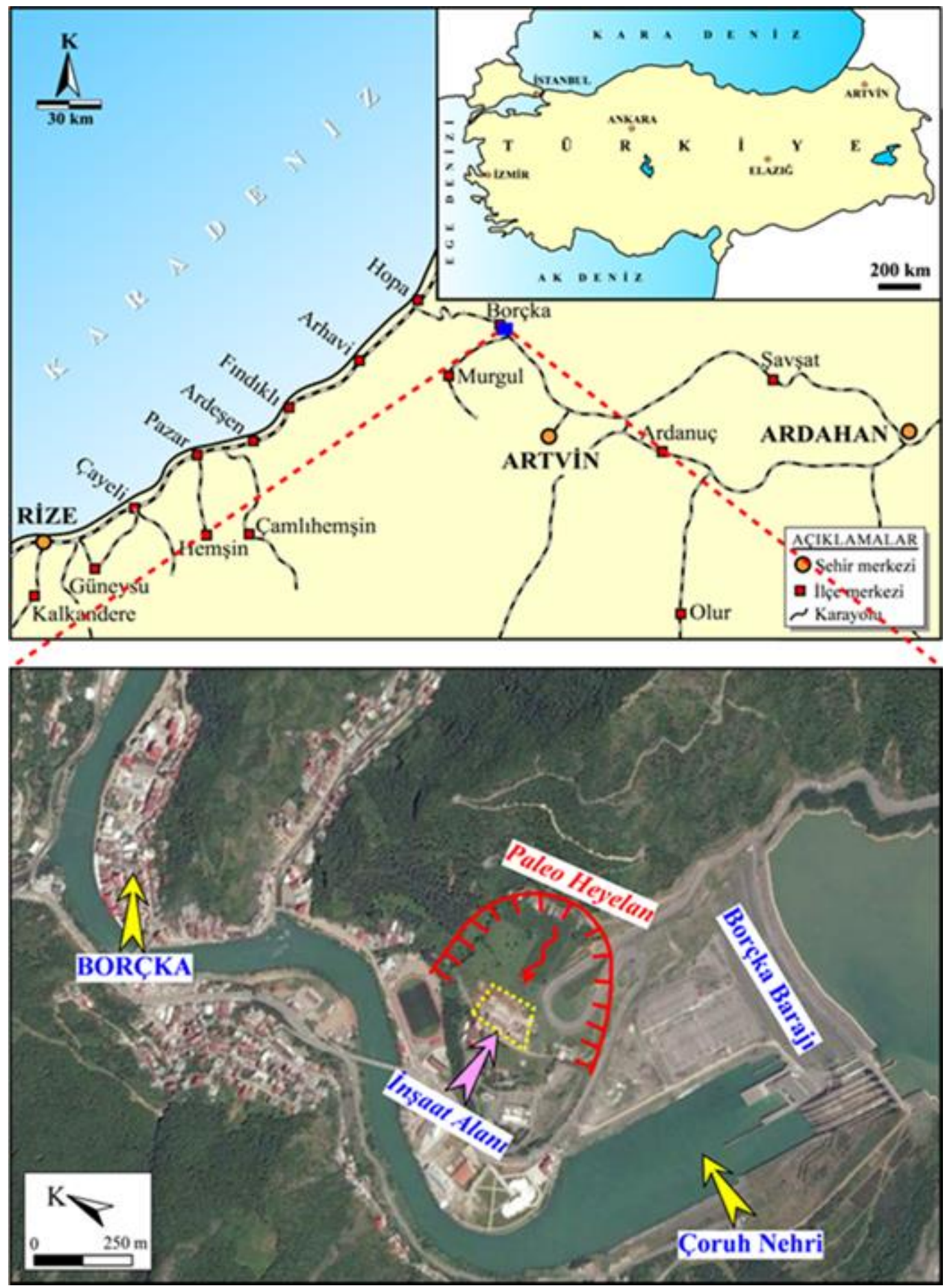

Şekil 1. Çalışma alanına ait yer bulduru haritası

\section{Mühendislik Jeolojisi Çalışmaları}

Çalışmanın konusunu oluşturan zemin şevinin bulunduğu alanda yeni Borçka devlet hastanesinin yapımı devam etmektedir. Söz konusu inşaat projesi, ihtiyaçları karşılamayan mevcut devlet hastanesinin yıkılarak aynı alana daha dayanıklı ve donanımlı olan yeni bir devlet hastanesinin yapılmasını kapsamaktadır. İnşaat aşamasına geçmeden önce arazi düzenlemesi kapsamında mevcut beton istinat duvarının ön sınırından itibaren yaklaşık $90 \mathrm{~m}$ uzunluğunda, $7 \mathrm{~m}$ yüksekliğinde ve $60^{\circ}$ eğim açısında geçici bir şev kazıs1 yapılmıştır. $\mathrm{Bu}$ zemin şevinin topuğundan itibaren $4 \mathrm{~m}$ uzaklıkta hastane binasının inşasına başlanılmıştır. Ancak, bölgedeki mevsimsel koşullara bağlı olarak aşırı yağışlar nedeniyle doygun hale gelen zemin şevinde kalıcı şevlendirme işlemine geçilmeden yenilmeler meydana gelmiştir. Gerileyen biçimde gelişen çatlaklar şev sınırından yaklaşık $80 \mathrm{~m}$ uzaklıktaki üst seviyelere kadar yayılım göstermiştir. 


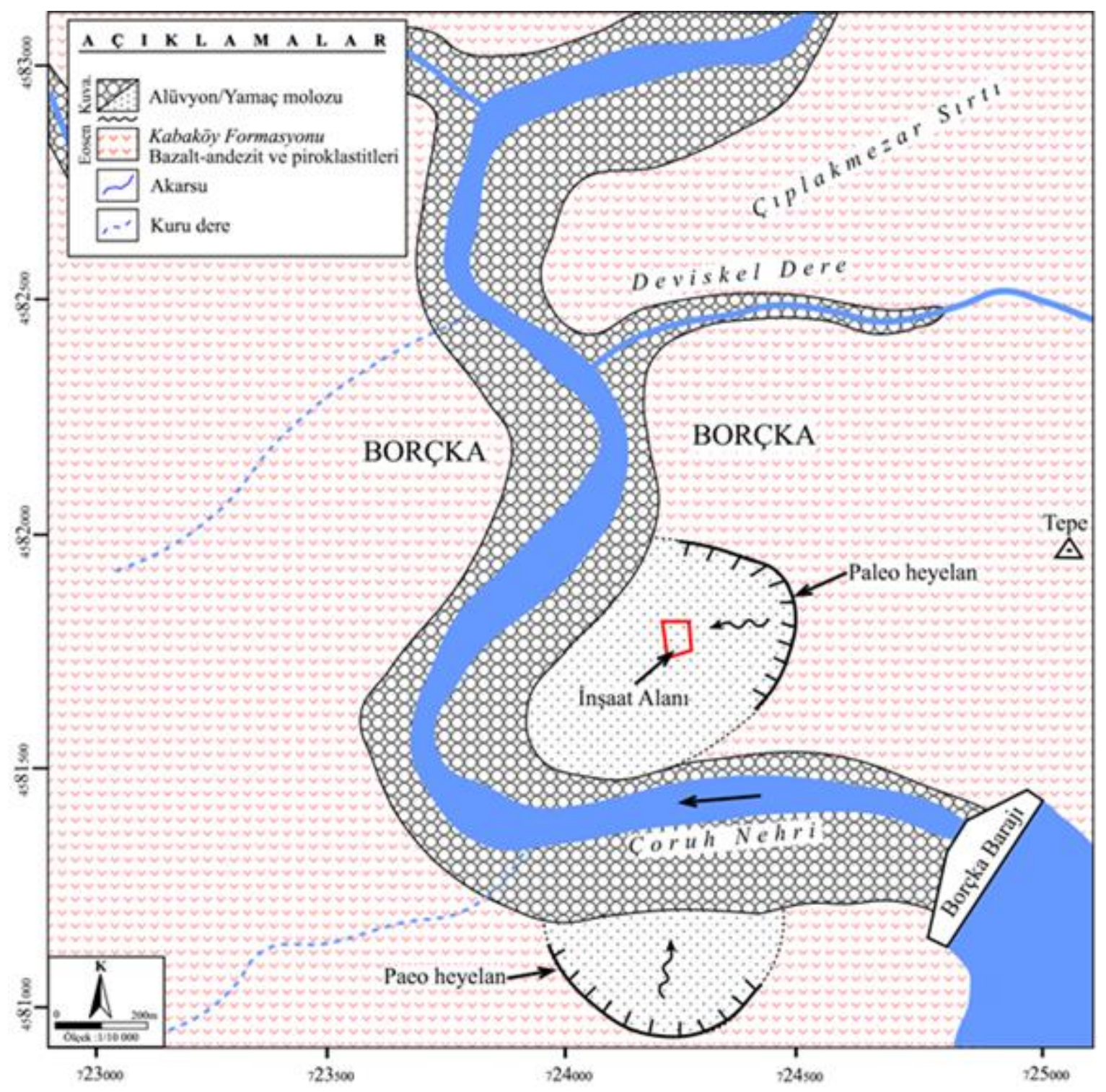

Şekil 2. Çalışma alanı ve çevresine ait jeoloji haritası

Şev topuğuyla hastane arasına birakılan $4 \mathrm{~m}$ uzunluğundaki mesafe, şevin ön yüzünde meydana gelen kaymadan dolayı tamamen kapanmıştır (Şekil 3). Bu duraysızlık problemini mühendislik jeolojisi açısından araştırmak amacıyla gerçekleştirilen çalışmalar arazi, laboratuvar ve duraylılık analizi çalışmaları olmak üzere üç aşamada yürütülmüştür. Yapılan çalışmalardan elde edilen sonuçlar aşağıdaki bölümlerde sunulmuştur;

\subsection{Arazi Çalışmaları}

Arazi çalışmaları kapsamında yenilmenin gerçekleştiği yamaç boyunca yüzey ve yeraltı çalışmaları gerçekleştirilmiştir. Çalışma alanı içinde yüzeylenen zeminle ilgili detaylı bilgiler elde etmek ve zeminin kalınlığındaki değişim aralıklarını tespit etmek amaciyla yeraltı suyu ölçümlerini de içerecek şekilde araştırma sondajları yapılmıştır. $\mathrm{Bu}$ sondajlardan 5 tanesi (SK 1-5) inşaat alanında kazı öncesinde, 3 tanesi (HSK 1-3) ise kayma olayından hemen sonra yamaç üstünde açılmıştır (Şekil 4). Sahada açılan sondajların içerisinde en derin olanı 40 m (HSK 2) olmasina rağmen bu derinlikte ana kaya kesilememiştir. Yürütülen sondaj çalışmaları neticesinde yamaç molozunun iki farklı zemin seviyesinden oluştuğu saptanmıştır. Üst seviyedeki killi-siltli zeminin kalınlığ 1 5.5-24.0 m arasında değişmektedir. $\mathrm{Bu}$ derinliklerden sonra ise kuyu sonuna kadar kumlu-çakıllı zemin seviyesi kesilmiştir. Sondaj kuyularında yapılan ölçümlere göre yeraltı su tablasının 3.0-18.0 m arasında olduğu gözlemlenmiştir (Tablo 1). HSK 2 nolu sondaj kuyusuna inklinometre borusu $(\varnothing$ : $70 \mathrm{~mm}$ ) yerleştirilerek 18 Aralık 2016-11 Ocak 2017 tarihlerini kapsayan dönemde inklinometre cihazı ile kuyu eksenlerinin düşey sapmaları tespit edilmeye çalışılmıştır. 

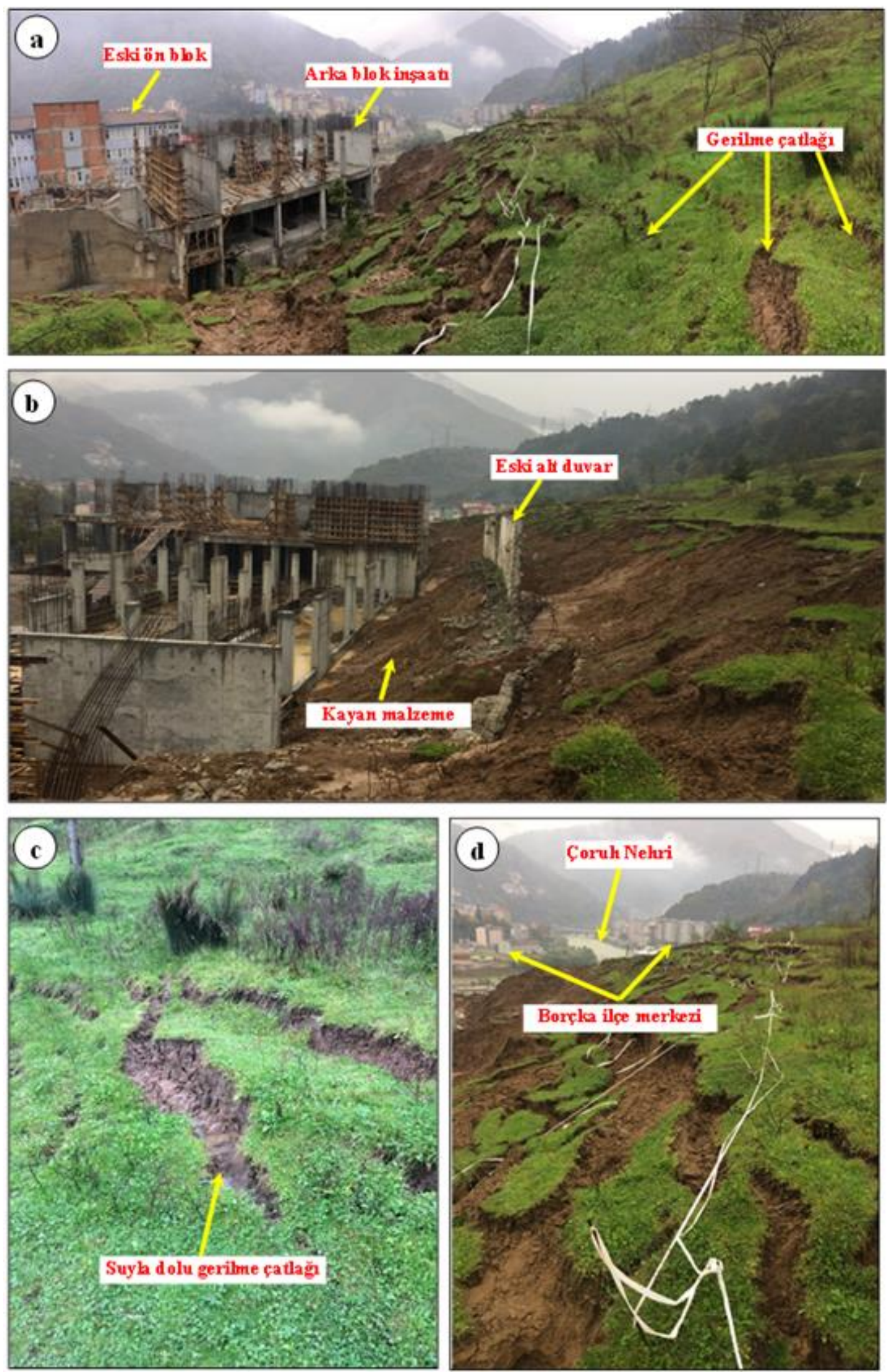

Şekil 3. Zemin şevinde meydana gelen gerilme çatlakları

Ölçüm hassasiyetinin diğer yöntemlerden daha yüksek olması sebebiyle zeminde gelișebilecek çok yavaş hareketler bu yöntemle belirlenmeye çalışılmıştır. Yapılan inklinometre ölçümlerinde gözlenen ana hareketin yüzeyden $20.5 \mathrm{~m}$ derinlikteki killi-siltli seviye ile kumlu-çakıllı seviye dokanağına yakın bir yerde geliştiği tespit edilmiştir (Şekil 5). Ayrıca, inklinometre 
ölçümlerinde killi-siltli zemin seviyesi içerisinde de yüzeyden 3,9 ve $13 \mathrm{~m}$ derinliklerde ana yenilmeden daha büyük ikincil yenilmelerin geliştiği gözlemlenmiştir (Şekil 5). Çalışma alanındaki zemin profilini ortaya çıkarmak ve P-S dalga hızları yardımıyla zeminin dinamik elastik parametrelerini belirlemek amaciyla 1 profil boyunca sismik kırılma yöntemi kullanılarak jeofizik çalışmalar gerçekleştirilmiştir (Tablo 2, Şekil 4). Sismik kırılma çalışmasının yapıldığı lokasyonda killi-siltli seviyenin derinliği $3.5 \mathrm{~m}$ olarak saptanmıştır. Dolayısıyla her iki zemin seviyesiyle ilgili dinamik parametreler bu lokasyonda kolaylıkla elde edilmiştir.

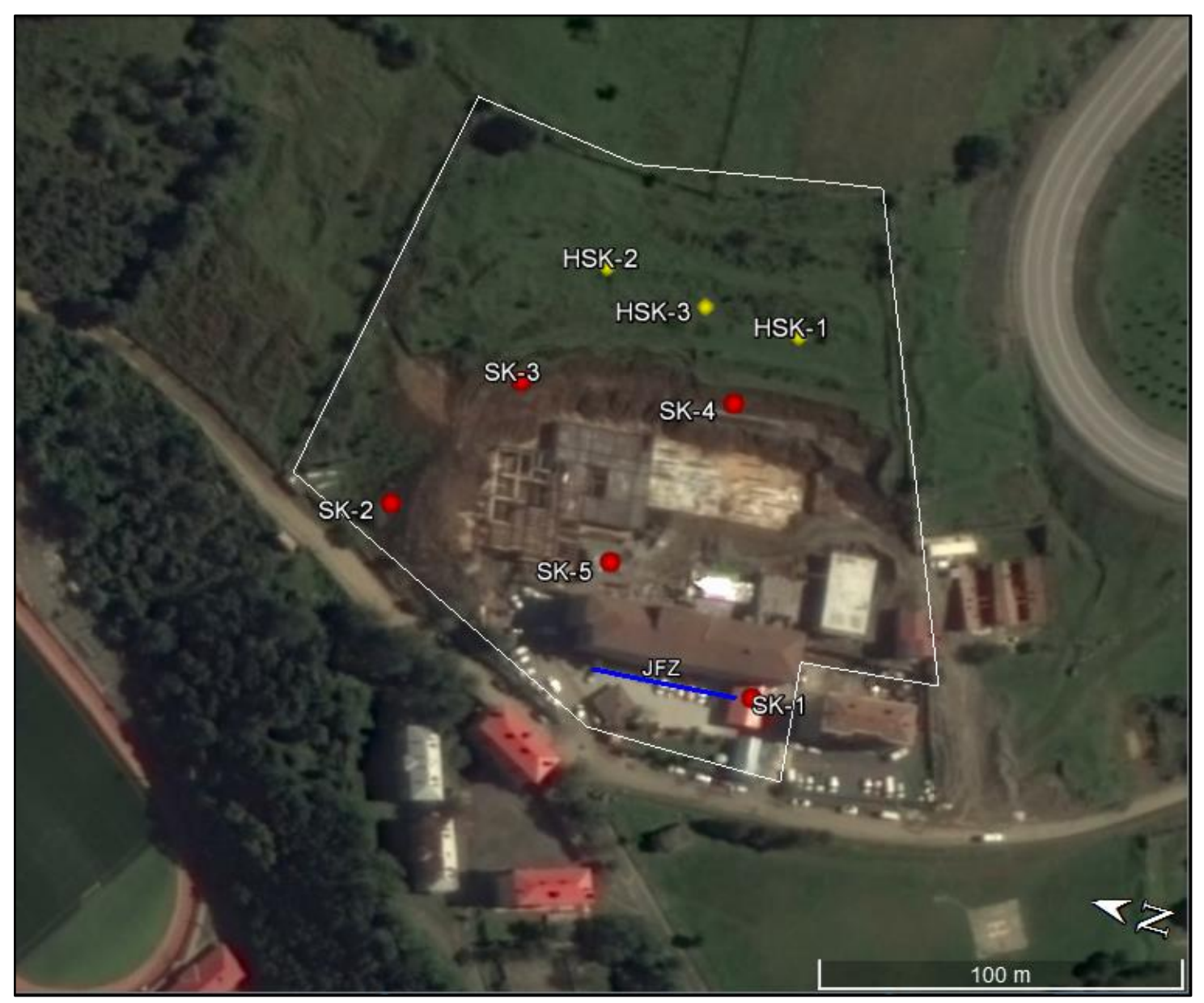

Şekil 4. Çalışma alanı içindeki sondajların ve sismik kırılma hattının uydu fotoğrafındaki görünümü

Tablo 1. Çalışma alanında yapılan sondajlara ait teknik bilgiler

\begin{tabular}{|l|l|l|l|l|l|}
\hline $\begin{array}{l}\text { Kuyu } \\
\text { no }\end{array}$ & $\begin{array}{l}\text { Kuyu } \\
\text { derinliği } \\
(\mathbf{m})\end{array}$ & $\begin{array}{l}\text { Kuyu kotu } \\
(\mathbf{m})\end{array}$ & $\begin{array}{l}\text { YASS } \\
\text { derinliği } \\
(\mathbf{m})\end{array}$ & $\begin{array}{l}\text { Y } \\
\text { (Sağa) }\end{array}$ & $\begin{array}{l}\text { X } \\
\text { (Yukarı) }\end{array}$ \\
\hline SK 1 & 10.00 & 83 & 7.90 & 724193 & 4581769 \\
\hline SK 2 & 15.00 & 85 & 3.00 & 724219 & 4581864 \\
\hline SK 3 & 20.00 & 94 & 18.00 & 724245 & 4581836 \\
\hline SK 4 & 20.00 & 95 & 12.00 & 724262 & 4581786 \\
\hline SK 5 & 20.00 & 90 & 18.00 & 724231 & 4581815 \\
\hline HSK 1 & 34.00 & 156 & 3.00 & 724272 & 4581586 \\
\hline HSK 2 & 40.00 & 157 & 4.00 & 724273 & 4581610 \\
\hline HSK 3 & 34.00 & 156 & 3.00 & 724276 & 4581637 \\
\hline
\end{tabular}


Tablo 2. Sismik kırılma yöntemine göre belirlenen dinamik-elastik parametreler

\begin{tabular}{|l|l|l|l|l|}
\hline Tabaka no & $\mathbf{V}_{\mathbf{p}}(\mathbf{m} / \mathbf{s})$ & $\mathbf{V}_{\mathbf{s}}(\mathbf{m} / \mathbf{s})$ & $\mathbf{E}_{\mathbf{d}}(\mathbf{M P a})$ & $\mathbf{v}$ \\
\hline 1 (killi-siltli seviye) & 622 & 335 & 441 & 0.30 \\
\hline $\begin{array}{l}\text { 2 (kumlu-çakı1lı } \\
\text { seviye) }\end{array}$ & 962 & 513 & 1159 & 0.30 \\
\hline \multicolumn{2}{|l|}{$\mathrm{V}_{\mathrm{p}}$ : boyuna dalga hızı, $\mathrm{V}_{\mathrm{p}}$ : enine dalga hızı, $\mathrm{E}_{\mathrm{d}}:$ deformasyon modülü, v: Poisson oranı } \\
\hline
\end{tabular}

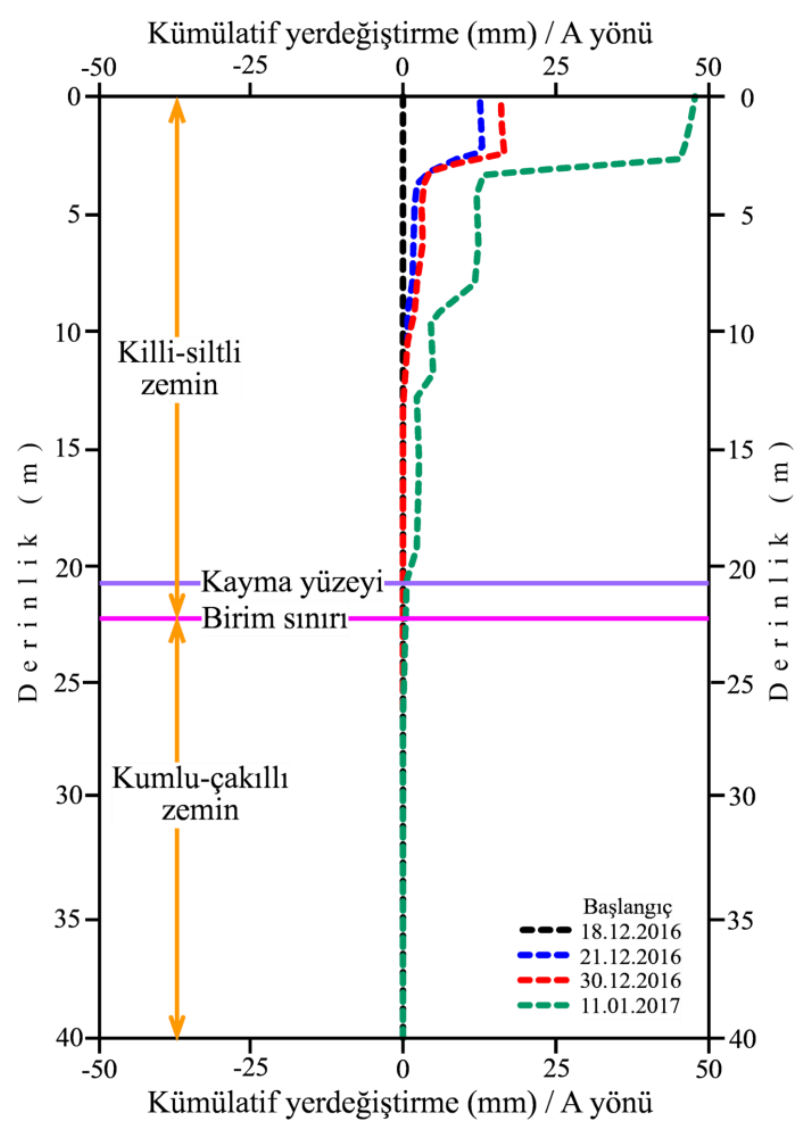

Şekil 5. HSK 2 nolu kuyuya ait inklinometre okumalarında tespit edilmiş derinlik-hareket miktarları ilişkisi

\subsection{Laboratuvar Çalışmaları}

Sondajlardan derlenen örselenmiş ve örselenmemiş zemin örnekleri üzerinde dane boyu dağılımı, kıvam limitleri, su muhtevası ve birim hacim ağırlık özelliklerini belirlemeye yönelik laboratuvar deneyleri gerçekleştirilmiştir (ASTM, 2005, 2007, 2009). Örselenmiş zemin örnekleri Birleştirilmiş Zemin Sınıflamasına (USCS) göre sınıflandırılmıştır (ASTM, 2006). Laboratuvar deneyleri sonucunda yamaç molozunun üst seviyesinin düşük plastisiteli kil (CL) zemin sınıfinda olduğu belirlenmiş olup, ortalama su içeriği ve birim hacim ağırlığı ise sırasıyla \% 22.9 ve $19.2 \mathrm{kN} / \mathrm{m}^{3}$ olarak saptanmıştır. Zemine ait kayma dayanımı parametrelerini (kohezyon ve içsel sürtünme açısı) belirlemek için 2.5-9.0 m arasındaki derinliklerden alınan numuneler üzerinde deformasyon kontrollü kesme kutusu deneyi yapılmıştır (ASTM, 2017). Deney sonuçlarına göre ortalama tepe kohezyon ve içsel sürtünme açısı sırasıyla $53.46 \mathrm{kPa}$ ve $11^{\circ}$ olarak saptanmıştır (Tablo 3). Ancak, yamaç molozunun alt seviyesindeki kumlu-çakıllı zeminden örselenmemiş örnekleme yapılamadığından birim hacim ağıllığı $22 \mathrm{kN} / \mathrm{m}^{3}$, kohezyonu $5 \mathrm{kPa}$ ve içsel sürtünme açıs1 da $30^{\circ}$ olarak seçilmiştir. Zemin sınıfı ise GM (siltli çakıl) olarak alınmıştır. $\mathrm{Bu}$ değerler seçilirken Hunt (1986) tarafindan kohezyonsuz zemin malzemeleri için önerilmiş sınıflandırma tablolarından yararlanılmıştır.

\subsection{D ve 3D FEM-SSR Durayllik Analizleri}

Çalışma alanındaki yenilme sorununun gözlendiği zemin şevin duraylılığının araştırılmasında 2D analiz yapan sonlu elemanlar tabanl "RS2 v9.0" (Rocscience Inc., 2017) ve 3D analiz yapan "RS3 
v1.0" (Rocscience Inc., 2016) bilgisayar programlarından yararlanılmıştır. Sahada yapılan araştırma sondajlarından elde edilen veriler kullanılarak zemin profili oluşturulmuş ve analiz modeli çizilmiştir. İlk olarak yenilmenin geliştiği şevin duraylılığ $2 \mathrm{D}$ analizi ile araştırılmış, sonrasında elde edilen çıktılar 3D analizi sonuçları ile karşıllaştırılmıştır.

Tablo 3. Yamaç molozunun üst seviyesindeki zemine ait indeks, fiziksel ve dayanım özellikleri

\begin{tabular}{|c|c|c|c|c|c|c|c|c|c|}
\hline \multirow{2}{*}{$\begin{array}{c}\text { Kuyu } \\
\text { no }\end{array}$} & \multirow{2}{*}{$\begin{array}{c}\text { Örnek } \\
\text { derinliği (m) }\end{array}$} & \multirow{2}{*}{$\begin{array}{c}\text { USCS } \\
\text { zemin sınıf }\end{array}$} & \multirow{2}{*}{$\begin{array}{l}\omega \\
(\%)\end{array}$} & \multirow{2}{*}{$\begin{array}{c}\gamma_{n} \\
\left(k N / m^{3}\right)\end{array}$} & \multicolumn{3}{|c|}{ Kıvam limitleri (\%) } & \multirow{2}{*}{$\begin{array}{c}\mathbf{c} \\
(\mathbf{k P a})\end{array}$} & \multirow{2}{*}{$\begin{array}{c}\phi \\
\text { (derece) }\end{array}$} \\
\hline & & & & & $\mathbf{L L}$ & PL & PI & & \\
\hline SK 1 & $4.0-5.5$ & $\mathrm{CL}$ & 24.2 & 19.1 & 40 & 22 & 18 & 63.77 & 7 \\
\hline SK 2 & $2.5-3.0$ & $\mathrm{CL}$ & 20.8 & 19.3 & 50 & 25 & 25 & 34.33 & 17 \\
\hline SK 3 & $8.8-9.0$ & $\mathrm{CL}$ & 22.5 & 19.1 & 44 & 25 & 19 & 60.82 & 7 \\
\hline SK 4 & $6.0-6.5$ & $\mathrm{CL}$ & 24.0 & 19.2 & 45 & 25 & 20 & 54.94 & 11 \\
\hline Ort. & - & - & 22.9 & 19.2 & 45 & 24 & 21 & 53.46 & 11 \\
\hline
\end{tabular}

Analizlerde Mohr-Coulomb yenilme kriteri kullanılmış olup, 2D analizinde güvenlik sayısı FEM tabanlı Kayma Dayanımı Azaltma Yaklaşımı (FEM-SSR) uygulanarak saptanmıştır. Ancak, "RS3 v1.0" program1 duraylil1k analizlerinde bir güvenlik sayısı değeri vermediğinden analiz sonuçlarının karşılaştırmasinda şevde meydana gelen kayma gerilmelerinin yoğunlaştı̆̆ yerlerin konumlarından yararlanılmıştır. Yol ve yarma şevleri gibi doğal olmayan yüksek eğim açılı şevlerde hesap edilen güvenlik sayısı $\left(\mathrm{G}_{\mathrm{s}}\right)$ değerinin duraylılık için $\mathrm{Gs}>1.5$ olması gerekmektedir (Mines Branch, Canada, 1972). Yapılan duraylılık analizlerinde tepe kayma dayanımı parametreleri kullanıldığından zeminin doğal durumu için statik koşullardaki kabul edilebilir güvenlik sayısı 1.5 olarak seçilmiştir.

Hazırlanan 2D ve 3D modellerinde detay analiz için hassas zonlama yapılmış ve üç dügüum noktalı üçgen şekilli sonlu elemanlar kullanılmıştır. Çözümlemeler şev eğimi boyunca değişen gravite yükleri altında yapılmıştır. Her bir sonlu elemanın üstündeki malzemenin ağırlığı yardımıyla elemandaki düşey gerilmeler tanımlanmıştır. Gerilme oranı, yüzey kazıları için hidrostatik basınç gerilmesini temsil etmesi amaciyla 1 olarak (yatay gerilme=düşey gerilme) girilmiştir. Şevin sağ, sol ve alt yüzeylerindeki yer değiştirmenin sıfır olması için sınırlandırılmış, üst yüzeyi ise deformasyonları saptamak için açık bırakılmıştır (Şekil 6a, 7a).

Yamaç molozunun üst seviyesi için $E_{d}$ ve $v$ değerleri sirasiyla $441 \mathrm{MPa}$ ve 0.30 , alt seviyesi için de sirasiyla $1159 \mathrm{MPa}$ ve 0.30 olarak modellere girilmiştir. Benzer şekilde yamaç molozunun üst seviyesi için $\mathrm{c}, \phi$ ve $\gamma$ değerleri sırasılyla $53.46 \mathrm{kPa}, 11^{\circ}$ ve $19.2 \mathrm{kN} / \mathrm{m}^{3}$ olarak, alt seviyesi için de sırasıyla $5 \mathrm{kPa}, 30^{\circ}$ ve $22 \mathrm{kN} / \mathrm{m}^{3}$ olarak analiz modellerine tanımlanmıştır.
İlk aşamada, şevin duraylılı̆̆ 2 D FEM-SSR yöntemiyle incelendiğinde güvenlik sayısı değeri $\mathrm{G}_{\mathrm{s}}: 1.17$ olarak belirlenmiştir. Analizlerde kayma dayanımı parametrelerinin tepe değerleri dikkate alındığından yenilmenin başladığı zemin şevi için yüksek güvenlik sayılarının elde edilmesi normaldir. $\mathrm{Bu}$ sonuç kabul edilebilir güvenlik sayıs1 olan 1.5 'den küçüktür ve şevin duraysız olduğunu göstermektedir. Belirlenen kayma yüzeyinin başlangıç kısmı yani kayma gerilmelerinin yoğunlaştığ 1 yer yamacın üst kotlarındaki uzak bir mesafeden başlayıp kumluçakıllı seviyenin dokanağına yakın bir yerden geçerek açılan şevin taban kısmında son bulmaktadır. Yapılan 2D analizi sonucunda sahadaki yenilme mekanizmasının birleşik kayma modeline uyduğu görülmüştür (Şekil 6b).

İkinci aşamada, 2D analizinden elde edilen sonuçları karşılaştırmak için oluşturulan 3D analiz modelinde kazı genişliğiyle aynı olacak şekilde model genişliği $90 \mathrm{~m}$ olarak girilmiştir. Yüzey topoğrafyasında sonuçları etkileyecek engebe farklılıkları mevcut olmadığından 2D modelinde temel alınan topoğrafyanın aynısı kullanılmıştır. Yapılan analizler sonucunda kayma gerilmeleri 2D analizinden elde edilen sonuçlarla uyumlu olacak şekilde yamacın üst kotlarındaki uzak bir mesafeden başlayıp kumlu-çakıllı seviyenin dokanağına yakın bir yerden geçerek açılan şevin taban kısmında sonlandığı saptanmıştır. Ancak, 2D analiz çıktısı 3D analizine göre tutucu davranarak kayma yüzeyinin taç kısmını biraz daha geriden başlatmıştır (Şekil 6b, 7c). Oluşan kayma gerilmelerinin yoğunlaştı̆̆ 1 yerler dikkate alındığında olası yenilmenin tabanı düzlemsele yakın kaşık şekilli bir yenilme modeline uyduğu anlaşılmaktadır (Şekil 7b, c). Yapılan 2D ve 3D duraylılık analizleri inklinometre sonuçlarıla da uyumlu olarak benzer sonuçlar vermiş ve şevin desteklenmesi gerekliliğini ortaya konmuştur. 


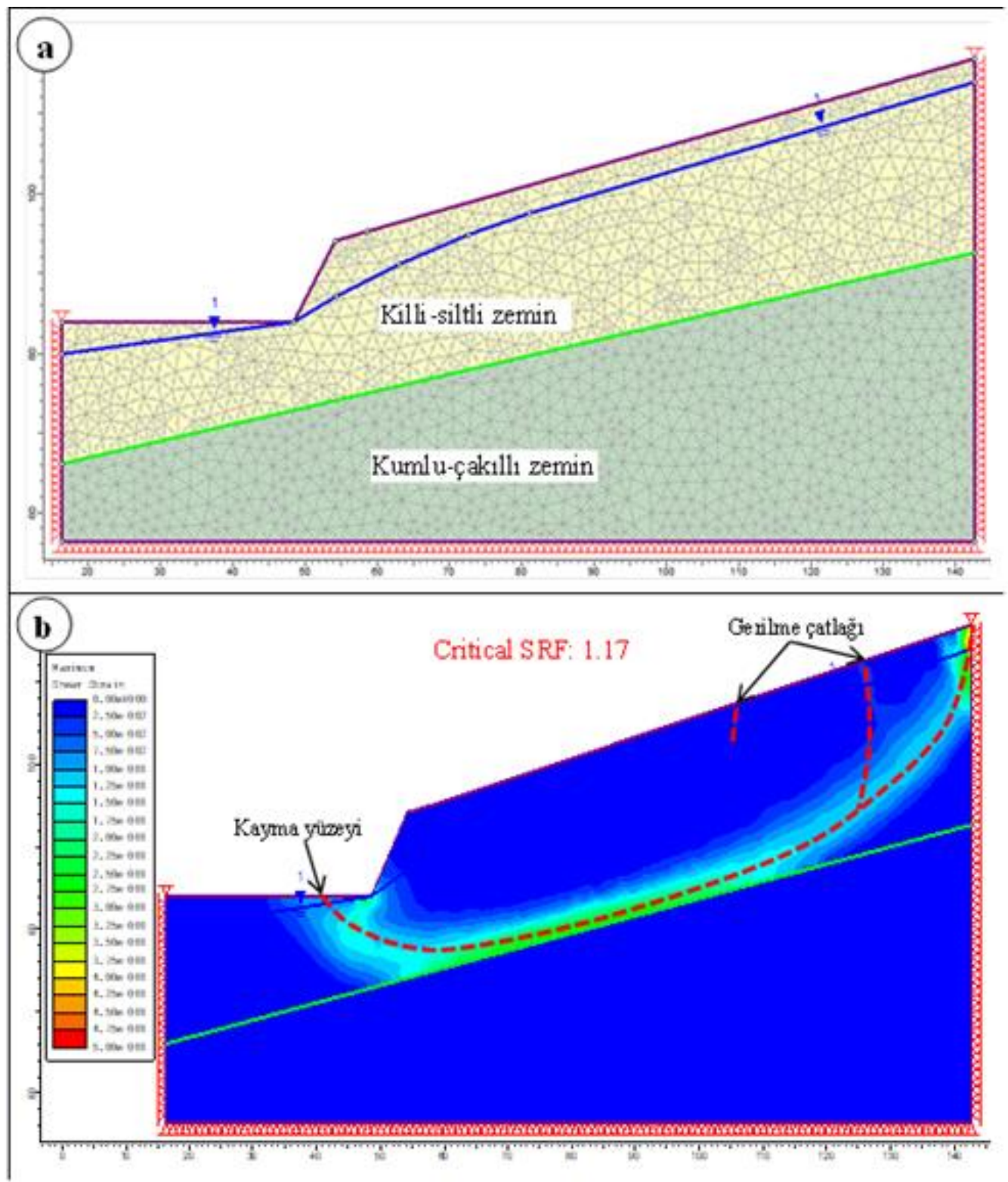

Şekil 6. (a) 2D analiz modeli ve (b) FEM-SSR duraylılık analizi sonucu

\section{Sonuçlar ve Öneriler}

Bu çalışma kapsamında, Yeniyol (Borçka-Artvin) Mahallesi'deki yeni devlet hastanesinin inşaatı için açılan zemin şevinde meydana gelen duraysızlık sorunu mühendislik jeolojisi açısından araştırılmıştır. Elde edilen sonuçlar aşağıda özet olarak sunulmuştur;

1) Duraysızlık probleminin gözlendiği yamaçta yapılan sondaj ve sismik kırılma çalışmaları sonucunda yamaç molozunun üstten alta doğru killi-siltli ve kumlu-çakıllı olmak üzere iki seviyeden oluştuğu saptanmıştır.

2) Yamaç molozunun üst seviyesindeki killi-siltli birimden alınan örselenmiş numunelerde zemin sınıfinın düşük plastisiteli kil (CL) olduğu belirlenmiş̧ir. Kayma dayanımı parametrelerini saptamak için örselenmemiş örnekler üzerinde yapılan kesme kutusu deneylerinde ortalama tepe kohezyon ve içsel sürtünme açısının sırasıyla $53.46 \mathrm{kPa}$ ve $11^{\circ}$ olduğu saptanmıştır. Ancak, yamaç molozunun alt seviyesindeki kumlu-çakıllı zeminden örselenmemiş örnekler alınamadığından kohezyonu $5 \mathrm{kPa}$, içsel sürtünme açısı da $30^{\circ}$ olarak seçilmiştir. Zemin sınıfı ise GM (siltli çakıl) olarak alınmıştır.

3) Yapılan sismik kırılma çalışması yardımıyla yamaç molozunun üst seviyesi için $E_{d}$ ve $v$ değerleri sirasıyla $441 \mathrm{MPa}$ ve 0.30 olarak, alt seviyesi için ise sırasıyla $1159 \mathrm{MPa}$ ve 0.30 olarak hesaplanmıştır. 

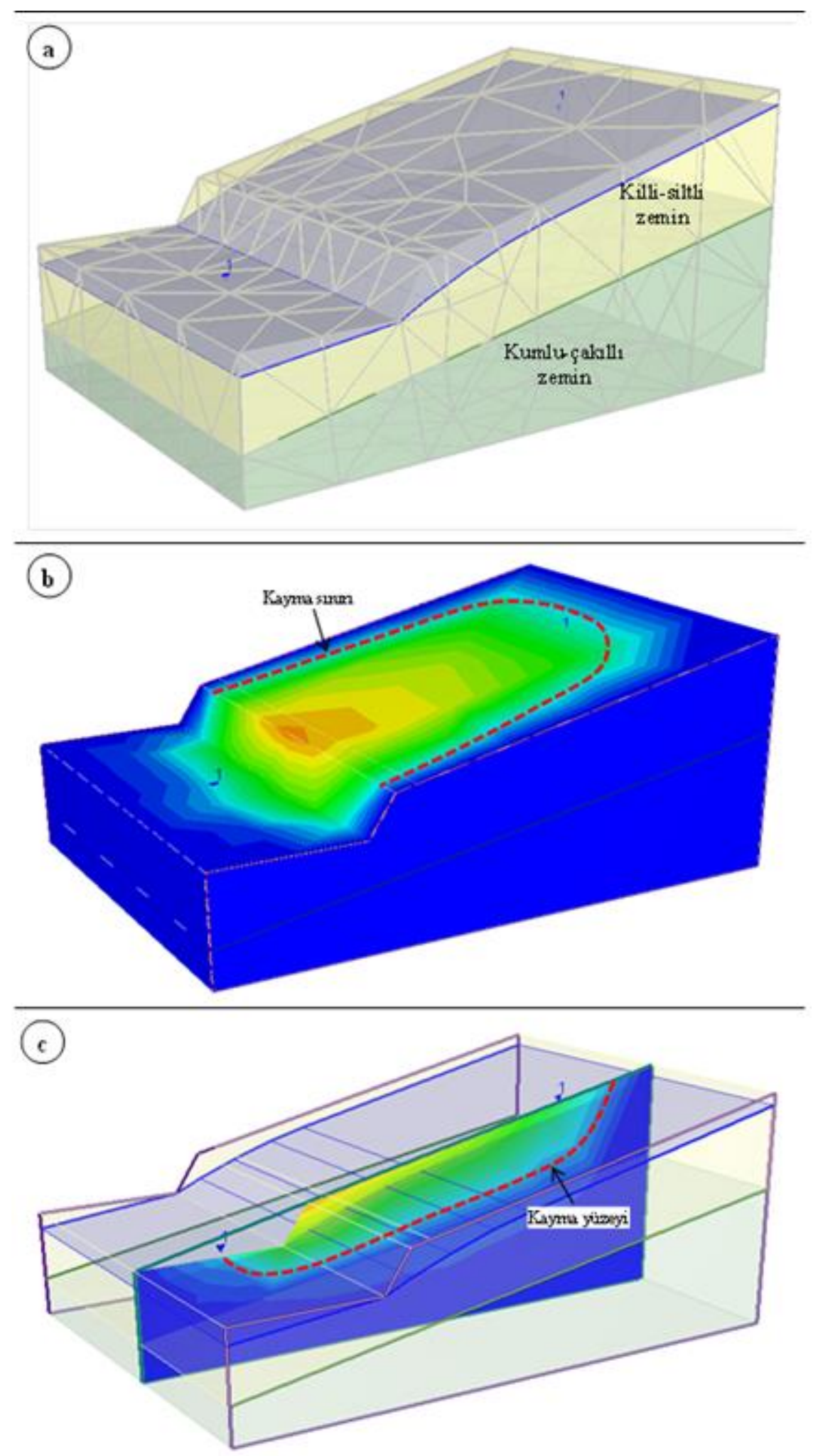

Şekil 7. (a) 3D analiz modeli, (b) FEM-SSR duraylılık analizi sonucu ve (c) 2D kesit görünümü

4) Yapılan inklinometre okumalarına göre ana kaymanın yüzeyden $20.5 \mathrm{~m}$ derinlikteki killi-siltli seviye ile kumlu-çakııllı seviye dokanağına yakın bir yerde geliştiği tespit edilmiştir. Ayrıca, killisiltli zemin seviyesi içerisinde de yüzeyden 3, 9 ve $13 \mathrm{~m}$ derinliklerde ana yenilmeden daha büyük ikincil yenilmelerin geliştiği gözlemlenmiştir.
5) Çalışma alanındaki şevin duraylılığını araştırmak için 2D ve 3D FEM-SSR yöntemleri kullanılarak sayısal analizler yapılmıştır. Yapılan 2D analizine göre kayma yüzeyinin başlangıç kısmı yamacın üst kotlarındaki uzak bir mesafeden başlayıp kumlu-çakıllı seviyenin dokanağına yakın bir yerden geçerek açılan şevin 
taban kısmında son bulmaktadır. 2D analizi ile benzer sonuçlar veren 3D analizi ise tutucu davranarak kayma yüzeyinin taç kısmını biraz daha geriden başlatmıştır. Elde edilen sonuçların inklinometre ölçümleriyle uyumlu olduğu görülmüştür. Duraysızlık problemleri gerçekte üç boyutlu olduğundan yapılan 2D analizlerinin 3D analizler ile desteklenmesi tasarımın doğruluğuna ve güvenirliğine katkıda bulunacaktır.

6) Duraylılık analizleri ve inklinometre ölçüm sonuçları, şevin dengede olmadığını ve desteklenmesi gerektiğini göstermektedir. Kazıklı destekleme yöntemi uygulanmas1 durumunda kazıkların kumlu-çakıllı zemin biriminin içine inecek şekilde soketlenmesi gerekmektedir. Demir donatılı kazıkların yeraltı suyunun akışını engellememesi için şevin doğrultusu boyunca birer boşluk bırakarak imal edilmesi ve imalat sonrasinda yanal toprak basinciyla deforme olmaması için başlık kirişi ile sabitlenmesi gereklidir. Sahada uygulanacak fore kazık tipinin seçimine, sayısının ve sıra adedinin belirlenmesine hazırlanacak fore kazık projesi ile karar verilmelidir.

\section{Teşekkür}

Yazar bu çalışmayı destekleyen Ustabaşlar İnş. ve Tic. Ltd. Şti.'ye teşekkür eder.

\section{Kaynaklar}

Alemdağ, S., Akgün, A., Kaya, A. ve Gökceoğlu, C., 2014. A large and rapid planar failure: causes, mechanism and consequences (Mordut, Gumushane, Turkey). Arabian Journal of Geoscience, 7 (3), 1205-1221.

Alemdağ, S., Kaya, A., Karadağ, M., Gürocak, Z. ve Bulut F., 2015. Utilization of the limit equilibrium and finite element methods for the stability analysis of the slope debris: an example of the Kalebasi district (NE Turkey). Journal of African Earth Science, 106, 134-146.

ASTM, 2005. Standard test methods for liquid limit, plastic limit and plasticity index of soils. Annual Book of ASTM Standards, ASTM D4318, Philedelphia, USA.

ASTM, 2006. Standard practice for classification of soils for engineering purposes (Unified Soil Classification System). Annual Book of ASTM Standards, ASTM D2487, Philedelphia, USA.

ASTM, 2007. Standard test method for particle-size analysis of soils. Annual Book of ASTM Standards, ASTM D422, Philedelphia, USA.
ASTM, 2009. Standard test methods for laboratory determination of density (unit weight) of soil specimens. Annual Book of ASTM Standards, ASTM D7263-09, Philedelphia, USA.

ASTM, 2017. Standard test method for consolidated undrained direct simple shear testing of fine grain soils. Annual Book of ASTM Standards, ASTM D6528-17, Philedelphia, USA.

Cheng, Y.M., Liu, H.T., Wei, W.B. ve Au, S.K., 2005. Location of critical three-dimensional nonspherical failure surface by NURBS functions and ellipsoid with applications to highway slopes. Computers and Geotechnics, 32 (6), 387-399.

Griffiths, D.V. ve Marquez, R.M., 2007. Threedimensional slope stability analysis by elastoplastic finite elements. Geotechnique, 57 (6), 537-546.

Gürocak, Z., Alemdağ, S. ve Musharraf, Z., 2008. Rock slope stability and excavatability assessment of rocks at the Kapikaya dam site Turkey. Engineering Geology, 96 (1-2),17-27.

Güven, İ.H., 1993. Doğu Pontidlerin jeolojisi ve 1/250000 ölçekli komplikasyonu. MTA, Ankara.

Hunt, R.E., 1986. Geotechnical engineering techniques and practices. McGraw-Hill Ryerson, Limited, $729 \mathrm{~s}$.

Kaya A., 2017. Geotechnical assessment of a slope stability problem in the Citlakkale residential area (Giresun, NE Turkey). Bulletin of Engineerıng Geology and the Environment, 76,875-889.

Kaya, A. , Akgun, A., Karaman, K. ve Bulut, F., 2016. Understanding the mechanism of slope failure on a nearby highway tunnel route by different slope stability analysis methods: a case from NE Turkey. Bulletin of Engineerıng Geology and the Environment, 75, 945-958.

Kaya, A., Alemdağ, S., Dağ, S. ve Gürocak, Z., 2016. Stability assessment of high-steep cut slope debris on a landslide (Gumushane, NE Turkey). Bulletin of Engineering Geology and the Environment, 75, 89-99.

Kaya, A., Bulut, F.ve Dağ S., 2018. Bearing capacity and slope stability assessment of rock masses at the Subasi viaduct site, NE Turkey. Arabian Journal of Geoscience, doi: 10.1007/s12517018-3477-7.

Kaya, A., Karaman K. ve Bulut, F., 2017. Geotechnical investigations and remediation design for failure of tunnel portal section: a case study in northern 
Turkey. Journal of Mountain Science, 14, 11401160.

Ketin, İ., 1966. Tectonic units of Anatolia. Journal of General Directorate of Mineral Research and Exploration (MTA), 66, 23-34.

Mines Branch, Canada, 1972. Tentative design guide for mine waste embankments in Canada. Department of Energy, Mines and Resources, Canada.

Rocscience Inc., 2016. RS3 v1.0 3D finite element analysis for rock and soil. Toronto, Ontario, Canada.

Rocscience Inc., 2017. RS2 v9.0 finite element analysis for excavations and slopes. Toronto, Ontario, Canada.
Singh, R., Kumar, U.R. ve Singh, T.N., 2017. Hill slope stability analysis using two and three dimensions analysis: A comparative study. Journal Geological Society of India, 89, 295302.

Wei, W.B., Cheng, Y.M. ve Li, L., 2009. Threedimensional slope failure analysis by the strength reduction and limit equilibrium methods. Computers and Geotechnics, 36 (1-2), 70-80.

Xiaolei, Q., Yunpeng, Ren., Suhe, Gao. ve Guoqiang, Wang., 2013. The 2D and 3D stability analysis of spreader for open-pit iron mine. Advanced Materials Research, 813, 263-268. 